\title{
The Effectiveness of Early Intensive Intervention in Modifying the Frequency of Repetitive Behavior for Children with ASD in Egypt
}

Eid G. Abo Hamza ${ }^{{ }^{*}}$ and Ahmed A. Helal ${ }^{1}$

Department of Mental Health, Faculty of Education, Tanta University, Tanta, Egypt

\begin{abstract}
The present study aims to test the effectiveness of an integrated training program for early intervention based on Applied Behavioral Analysis (ABA) to improve some of the repetitive behavior patterns (stereotyped behavior, self-harm behavior, compulsive behavior, ritual behavior, sameness behavior, unrestricted behavior) among a sample of children with autism. It uses an experimental approach, with experimental and control groups ( $\mathrm{N}=17$ for each group) and three-time interval assessments (pre, post and follow-up). The study uses several assessments such as the Goddard Measure of Intelligence, a Socio-economic Status Form (Abo Hamza \& Helal, 2013), and the Stereotyped Behavior Scale (RBS-R) [1]. Statistical analysis has been performed using the Pearson correlation, and Chi-square, MannWhitney, Eta-squared and $\mathrm{Z}$ tests for each time assessment from the two groups to identify interaction effects. Results indicate that the intervention program has a positive effect on modifying the stereotyped behavior patterns in both post- and first follow-up assessment (after two weeks). However, the study shows no positive effect for the second follow-up assessment (after two months).
\end{abstract}

\section{Introduction}

Basically, the first years of a child's life are considered to be one of the most important stages of his/her development in which his/her human personality is shaped through building its first blocks. Hence, the results of caring for children are not only useful for the children but also for society as a whole in the long term.

Therefore, one of the indicators of a nation's civilization is the extent of care assigned for children's upbringing in all phases. This is well-illustrated in the extent of its care and interest for children with special needs, because the negligence of this group leads to a plethora of problems that may increase their disability. Consequently, the guiding and therapeutic intervention seems a must for challenging these disability-centered problems.

Furthermore, children with special needs require a special style and curricula to deal with them. Children with autism spectrum disorder (ASD) top such groups that need intensive help in their education and care. As a result, their training and rehabilitation increase their concentration, competence and behavioural re-evaluation, which enable them to interact with their peers and socialize once again. The autistic child seems to have an attractive disposition and good health, yet he/she is passively isolated, performs repetitive actions, and is restrictively interested in something with which he/she uses to play; he/she flies into a rage if one takes it from him/her and enters a violent fit $[2,3]$.

Autism has become one of the most prevalent childhood affections of our generation, the second most common developmental disability, next to mental retardation, affecting an estimated 1 in 150 children [4]. Recently, reported frequencies for ASD across the whole world have approached $1 \%$ of the population. Autism is a lifetime neurodevelopmental disorder and is not curable.

There are generally three main characteristics used to determine an ASD, and these are usually present by the age of three. These characteristics are deficit in social interaction, verbal and nonverbal communication and repetitive patterns of behaviors and interests [5].
After scrutinizing the theoretical framework and literature, the researchers consider that the preparation of an integrated training program for early intervention based on $\mathrm{ABA}$ to modify the stereotyped behavior among children with ASD will give them, in effect, the use of their own potentials and the environmental factors surrounding them, which will give them the ability to adapt to their family and the surrounding environment, and help them to improve their academic performance.

The symptoms of autism and the behavior of children with ASD vary to the extent that it includes different developmental aspects: social, cognitive, linguistic, emotional, sensory and kinesthetic. Some of these children may repeat certain words, sounds or phrases. In addition, they show strong resistance if their daily routine is altered, and exhibit abnormal reactions to new experiences. Plus, children with ASD react to things more than others, and repeat certain physical movements. Thus, any change in the surrounding environment leads to increased feelings of distress and tension, and increase of these undesirable behaviours [6-8].

In fact, these behaviors are considered unusual behaviors that develop with age. These behaviors are characterized by confusion and are an impairment because the autistic child cannot properly evaluate the consequences, which may harm himself/herself and others. Thus, there was an urgent need to seek a method for intervention to modify these disruptive behaviors. Plus, the preparation of a behavioral and educational program to mitigate and modify these behaviors is one of the most important things that will affect them positively.

"Corresponding Author: Dr. Eid G. Abo Hamza, Department of Menta Health, Faculty of Education, Tanta University, Tanta, Egypt; E-mail: eabohamza@qu.edu.qa

Citation: Abo Hamza EG, Helal AA (2018) The Effectiveness of Early Intensive Intervention in Modifying the Frequency of Repetitive Behavior for Children with ASD in Egypt. Int J Psychol Behav Anal 4: 152. doi: https://doi.org/10.15344/2455$3867 / 2018 / 152$

Copyright: (c) 2018 Hamza et al. This is an open-access article distributed under the terms of the Creative Commons Attribution License, which permits unrestricted use, distribution, and reproduction in any medium, provided the original author and source are credited. 
This becomes clearer when we know the comorbidity of the problem; Hussein, Taha and Almanasef [9] reported that the prevalence of autism is about $100-200$ persons in every 10,000 in Egypt. Furthermore, Abd Elhamid, Howe and Reading [10] reported that the prevalence of emotional and behavioral symptoms was high as reported by both parents and teachers (abnormal total difficulties: teachers $34.7 \%$, parents $20.6 \%$; abnormal prosocial scores: teachers $24.9 \%$, parents $11.8 \%$ ). The prevalence of probable psychiatric diagnoses, however, was much lower (any psychiatric diagnosis $8.5 \%$; emotional disorder $2.0 \%$; conduct disorder $6.6 \%$; hyperactivity disorder $0.7 \%$ ). There are several and varied symptoms of autism, and behaviors displayed by children include various developmental aspects: social, cognitive, linguistic, emotional, and sensory and motor. This then raises the following question: Does early intervention have an impact in modifying the stereotyped behavior patterns (stereotyped behavior, self-harm behavior, compulsive behavior, ritual behavior, sameness behavior, unrestricted behavior) among a sample of children with autism? Consequently, this study is important for the following reasons:

1. It deals with one of the most important and serious classes of disability, that of autism, which has a clear impact on the aspects of a child's personality as a whole.

2. The positive results of the program will serve the children and the environment, and reduce parental stress.

3. To make a positive change in the personality and behavior of the child and cause a shift from a dependent child to a child depends on himself to some extent.

4. This study attempts to reduce the stereotyped behavior of children with ASD and give them some desired behaviors.

The present study aims to test the effectiveness of an integrated training program for early intervention based on some techniques of behavioural therapy, such as guidance and analysis tasks and reinforcement, modeling and training separate attempt, and some educational activities such as painting and social stories, music, exercise etc., to improve some of the patterns of behavior stereotyped of children with autism.

\section{Theoretical Framework}

In essence, stereotyped and ritualistic behaviors are considered one of the most observed behaviours of many autistic people. In fact, this behavior may be aggression towards others or in the form of selfinjury [11].

In the early years of the child's life, he/she does not show any desire to recognize things and play with the people surrounding him/her in his/her environment, and he/she does not possess the curiosity that is a distinctive feature of a young child in the early stages of his/ her life. In fact, the autistic child may grasp the toys and the things that are within his/her reach, but it is a random and limited action in terms of both quality and frequency without an aim. This occurs unintentionally and routinely in a way that lacks purposeful creativity and conceptualization or allusive play or symbolism. It may also lack imitation or pantomime and if he/she is engaged in a game, it would be rigid (monotonous, ritualistic or compulsive) and he/she often likes to rotate (himself/herself, around a table or the walls of a room or playground, or with a finger or a key ring in his/her hand). In addition, he/she is more likely to be attached to objects than to humans. Plus, the child repeats stereotyped movements, such as shaking his/her head or bending their trunk and head forward and backward, for a long time without fatigue or boredom, especially when the child is left alone without being occupied with a particular activity.

\section{Restricted and Repetitive Behavior}

One of the prominent features of ASD is restricted and repetitive behaviors; however these aspects are less commonly considered in research $[12,13]$. Therefore, there are unanswered questions relating to restricted and repetitive behaviors found within the ASD population. Until now, restricted and repetitive behaviors were considered the result of deficits in interaction and communication development [14]. However, a growing body of evidence would suggest that these attributes of behavior are distinctive from social and communication capabilities. For instance, individuals with High Functioning Autism (HFA) may show signs of significant impairments with respect to restricted and repetitive behaviors, and similar findings are also evident in individuals with Asperger's syndrome [15]. What is more, those who are not diagnosed with ASD but suffer from problems characterized by social impairments, language impairments (e.g., specific language impairment and social anxiety), or both, do not necessarily display restricted and repetitive behaviors. Interestingly, those without an ASD diagnosis who have disorders that are characterized by restricted and repetitive behaviors (e.g., ObsessiveCompulsive Disorder) do not necessarily display communication or social deficits. With respect to family studies that investigate the heritability of ASD, these indicate that there are certain genes that control for restricted and repetitive behaviors. This suggests there are independent genes that are separate from social and communication deficits $[16,17]$.

In studies that have compared restricted and repetitive behaviors between indviduals with ASD, developmental disabilities, neurological conditions, and psychiatric disorders are used to signal how restricted and repetitive behaviors manifest and how ASD is related to other conditions [12].

An investigation that compared stereotypic behaviors among 185 adults with ASD with another group of 1060 adults diagnosed with server intellectual disability (without ASD) [18]. It was found that $75 \%$ of the subjects with ASD and intellectual disability had stereotypy behavior that went over the cut-off point score [19]. These findings are supported by other results that have found repetitive behaviors found in those with autism and intellectual disabilities matched on key subject characteristics, e.g. age, IQ, and gender [20]. However, other research comparing ASD and other individuals with intellectual disabilities has found ASD sufferers show higher levels of repetitive behaviors. Furthermore, those with ASD tend to report higher levels of severity in many domains, including: compulsions, self-injurious behavior, and stereotyped motor behavior.

Obsessive and compulsive behaviors in those with autism compared with Obsessive-Compulsive Disorder (OCD), and anxiety disorders sufferers have been shown to have unwanted thoughts and feelings that drive certain behaviors, intended to reduce anxious feelings [21]. More research that has looked at autism and OCD found that autism sufferers had a more likely chance of hoarding behaviors, touching patterns, engaging in self-injurious actions, obsession (but not compulsion), were less likely to engage in checking behaviors and thoughts of aggression and desire [22]. 
Citation: Abo Hamza EG, Helal AA (2018) The Effectiveness of Early Intensive Intervention in Modifying the Frequency of Repetitive Behavior for Children with ASD in Egypt. Int J Psychol Behav Anal 4: 152. doi: https://doi.org/10.15344/2455-3867/2018/152

Page 3 of 16

With regard to the frequency and level of intensity of restricted and repetitive behaviors, this differs across individuals with ASD. In the DSM-5 it is reported as "restricted, repetitive, and stereotyped patterns of behavior, interests, and activities" [5]. In order to state whether these criteria are met accordingly, it is recommended that clinicians take on a reasonability in determining whether the client or patient displays at least one of the following behaviors:

1. Encompassing preoccupation with one or more stereotyped and restricted patterns of interest that is abnormal either in intensity or focus

2. Apparently inflexible adherence to specific, non-functional routines or rituals

3. Stereotyped and repetitive motor mannerisms (e.g., hand or finger flapping or twisting or complex whole body movements)

4. Persistent preoccupation with parts of objects.

\section{Early Interventions}

Treatments are readily available currently for autism. The treatment that has the greatest empirical support based on Applied Behaviour Analysis (ABA) is educational treatment $[23-26,7,8]$. What's more, Early Intensive Behavioural Intervention (EIBI) is a common method used on young children who suffer from autism [27]. This method of treatment integrates principles that are based on ABA in order to benefit children aged between 2 and 5 years old with autism (as well as other developmental disabilities; [3]. Early intervention involves operant learning procedures and improves social relevant behavior as shown by several studies using large and comprehensive research procedures in children with autism $[26,7,8]$.

There is a high success rate for early intervention, with only an estimated $10 \%$ of children making few or no improvements in intensive behavioral programs $[23,25,24,7,8]$. ABA based interventions are known to improve intellectual capabilities, as measured by intelligence tests, with the majority of children tested gaining higher levels of IQ scores over the course of one to six years of treatment $[23,28,25,7,8]$.

Improvements in language, social skills, self-help skills, and problematic behaviors have been shown by research to be less robust than IQ changes, but some children still show signs of improvements, to the extent that they are indistinguishable from their peers post intervention $[29,24,30]$

Finally, another known effect of ABA based treatment is the success rate of integrating children with autism into regular schools with other children after a minimum of two years of intensive therapy $[31,28,29,25,24,30,8]$. ABA programs are also found to be significantly more effective with 25 to 40 hours per week, when compared to other equally intensive interventions $[8,32,33]$.

As a result, if children with ASD are prevented from performing such rituals or stereotyped behaviors or they are interrupted, they will have a fit of anger [7]. There is another seminal feature in this regard, which is the persistence of a certain routine, and resistance to any change that occurs even if it is a slight change. It is known that these children initially show instability in any process, whether eating, sleeping, playing, or any other behavioral performance, but when they learn a certain way to perform anything, they strictly adhere to this way and work to apply it without the slightest change until they become slaves to this sterile routine [7].

As a result, if children with ASD are prevented from performing such rituals or stereotyped behaviors or they are interrupted, they will have a fit of anger [7]. There is another seminal feature in this regard, which is the persistence of a certain routine, and resistance to any change that occurs even if it is a slight change. It is known that these children initially show instability in any process, whether eating, sleeping, playing, or any other behavioral performance, but when they learn a certain way to perform anything, they strictly adhere to this way and work to apply it without the slightest change until they become slaves to this sterile routine [7].

Early intervention is an important means of reducing childhood disability and contributing to minimizing the problems that result from procrastination in the diagnosis of individuals with any disability or who are about to become disabled. Consequently, early intervention may help the child overcome their difficulties or enable treatment that may prevent the emergence of disability in its integrated form $[8,32,33]$.

In fact, behavior modification is one of the most widely used approaches to care for, educate and treat people with special needs. It is based on behavioral perception and the associated learning theories. Behavior modification is a systematic intervention to reorganize environmental events in order to produce desired behavioural evaluations $[8,32,33]$.

ABA comprises three stages: (A) a symbol to indicate the beginning of the targeted behavior; (B) the variable is intended to change the target behavior; and $(\mathrm{C})$ continue observation, but the treatment is removed to see whether the child will return to the starting point or not. This observation is to determine whether the behavior depends on the independent variable. The experimental variable is applied again to see if the behavioral change can be recovered. The analyst attempts to conduct an analysis of behavior, meaning that whenever a variable is applied, the behavior should decrease. This design strengthens analysis and is widely used [34,6-8].

The present study is based on two models of behavioral modification: the model of operant conditioning and social learning theory.

\section{Operant Conditioning Model}

The operant conditioning model is concerned with studying the laws of learning that are predominant of the procedural behavior. This model is based on Thorndike's laboratory research on instrumental conditioning, in particular the law of effect, and Burschner's research known as the experimental analysis of behavior and radical

$$
\begin{array}{lll}
\text { Consequences } & \text { Behavior } & \text { Antecedents } \\
\text { (C) } \longleftarrow & \text { (B) } & \text { (A) }
\end{array}
$$

Figure 1: The functional analysis of behavior. 
Citation: Abo Hamza EG, Helal AA (2018) The Effectiveness of Early Intensive Intervention in Modifying the Frequency of Repetitive Behavior for Children with ASD in Egypt. Int J Psychol Behav Anal 4: 152. doi: https://doi.org/10.15344/2455-3867/2018/152

Page 4 of 16

behaviorism. The Alexandrian behavioral philosophy (or so-called human behavior philosophy) had the greatest impact on the field of behavior modification [34].

Most researchers and practitioners who employ this model focus on behavior analysis in the natural environmental situation in which behavior occurs and the relationship of this behavior to the pre-and post-environmental variables (Figure 1).

According to this model, post-stimuli play a key role in the analysis and modification of behavior. Pre-stimuli, although they affect procedural behavior, have their effect on the dimension stimuli (behavior outcomes). This model also emphasizes the importance of studying apparent behavior using objective scientific methods [7]

\section{Social Learning Theory}

Founded by Albert Bandura, social learning theory aims to develop a comprehensive theory of biological, environmental and cognitive factors. The basic characteristic of this model is to clarify the learning process by relying on the role of cognitive processes or so-called mediational constructs. In this view, learning can occur without direct training or without direct impact on environmental conditions, but through observational learning, also called simulated learning or modeling [34,7]. It is thought that the human tendency to copy the behavior of others and then adopt this behavior themselves may cause an individual to adopt aggressive behavior in his/her interaction with others. Social learning theory considers that children learn a lot of behavioral styles, thoughts and feelings based on their observation of the behaviors of others $[34,7]$.

\section{The Study Hypotheses}

\section{Main Hypothesis}

There is a statistically significant effect of an integrative early intervention program in modifying the frequency of repetitive behavior for children with ASD (according to the total score of the repetitive behavior assessment).

This main hypothesis includes six sub-hypotheses as follows:

1. There is a statistically significant effect of an integrative training program for early intervention in modifying the stereotyped behavior (first dimension of the scale) in a sample of children with ASD.

2. There is a statistically significant effect of an integrative training program for early intervention in modifying the self-injurious behavior (second dimension of the scale) in a sample of children with ASD.

3. There is a statistically significant effect of an integrative training program for early intervention in modifying the compulsive behavior (third dimension of the scale) in a sample of children with ASD.

4. There is a statistically significant effect of an integrative training program for early intervention in modifying the ritualistic behavior (fourth dimension of the scale) in a sample of children with ASD.
5. There is a statistically significant effect of an integrative training program for early intervention in modifying the sameness behavior (fifth dimension of the scale) in a sample of children with ASD.

6. There is a statistically significant effect of an integrative training program for early intervention in modifying the restricted behavior (sixth dimension of the scale) in a sample of children with ASD.

\section{Methods}

\section{Participants}

The sample in this study consisted of (34) children with ASD of both genders (17 in controlled group, and 17 in experimental group). Both groups were from Tanta Bander which is a rural area in the middle of the delta of Egypt. The facility counselor diagnosed all participants with autism according to DSM-5 criteria. Therefore, the current research did not use any autism assessment again because participants were already diagnosed.

Participants' age ranged from 36 to 72 months, and their IQ range from 55 to 68 as assessed by the Goddard Measure of Intelligence. Additionally, all participants belonged to the same economic and social level, which is the moderate level. Table 1 presents the descriptive and demographic data for both groups. The 10 participants were divided into the following:

1. An experimental group that would receive an early intensive intervention based on ABA.

2. A control group that would receive treatment as usual.

\section{Instruments}

In order to collect data for this study, the researchers used three valid and reliable questionnaires, as follows:

\section{Goodenough-Harris drawingtest}

This assessment has been used to assess the intellectual ability for children aged between 3 and 15 years old. It is a nonverbal IQ assessment that can be applied individually or collectively. The assessment time takes between 10 and 15 minutes and the correction takes the same time. This assessment has been used in several Arabic studies in Arabic countries. Therefore, validation has been done by; reliability has been done by test-retest $(r=.68)$, split halves $(r=.89)$; and validity has been done using the correlation with Sanford-Bennet assessment $(\mathrm{r}=.79)$.

\section{Socio-economic status form (Abo Hamza \&Helal, 2013)}

The form was created by the researchers and it includes several questions to assess the economic, social and cultural levels of families. The form asks about the profession of the father and mother, their income and the number of family members. The researchers validated the socio-economic form by criterion and construct validity.

\section{Stereotyped behavior scale (RBS-R) [35]}

The RBS-R is a 43-item self-report questionnaire that is used to measure the breadth of repetitive behavior in children, adolescents, and 
Citation: Abo Hamza EG, Helal AA (2018) The Effectiveness of Early Intensive Intervention in Modifying the Frequency of Repetitive Behavior for Children with ASD in Egypt. Int J Psychol Behav Anal 4: 152. doi: https://doi.org/10.15344/2455-3867/2018/152

Page 5 of 16

Likert scale: 0-Behavior does not occur; 1-Behavior occurs and is a mild problem; 2-Behavior occurs and is a moderate problem; 3-Behavior occurs and is a severe problem, and raters are asked to refer to the previous month when completing the scale. On the last question, participants are asked to "lump together" all of the behaviors described in the questionnaire, and provide a rating for how much of a problem these repetitive behaviors are overall, on a scale from 1 to 100: 1 -Not a problem at all, through to 100-As bad as you can imagine [11].

The items of the RBS-R have been conceptually grouped (i.e., based on clinical experience) into six subscales. These include:
1. Stereotyped Behavior (movements with no obvious purpose that are repeated in a similar manner).

2. Self-injurious Behavior (actions that cause or have the potential to cause redness, bruising, or other injury to the body).

3. Compulsive Behavior (behavior that is repeated and performed according to a rule or involves things being done "just so").

4. Ritualistic Behavior (performing activities of daily living in a similar manner).

5. Sameness Behavior (resistance to change, insisting that things stay the same).

6. RestrictedBehavior(limitedrangeoffocus, interest,oractivity) [11].

\begin{tabular}{|c|c|c|c|c|}
\hline Group & Time of Assessment & Measurement & $M$ & $S D$ \\
\hline \multirow[t]{3}{*}{ Experimental } & Pre-Assessment & Total Scoreof Repetitive Behavior & 64.60 & 9.63 \\
\hline & Post-Assessment & Total Score of Repetitive Behavior & 41.40 & 4.92 \\
\hline & Follow-up Assessment & Total Score of Repetitive Behavior & 41.40 & 5.31 \\
\hline \multirow[t]{2}{*}{ Control } & Pre-Assessment & Total Score of Repetitive Behavior & 64.60 & 9.63 \\
\hline & Post-Assessment & Total Score of Repetitive Behavior & 78.20 & 9.60 \\
\hline \multirow[t]{3}{*}{ Experimental } & Pre-Assessment & The Stereotyped Behavior & 9.40 & 4.50 \\
\hline & Post-Assessment & The Stereotyped Behavior & 5.60 & 3.20 \\
\hline & Follow-up Assessment & The Stereotyped Behavior & 5.60 & 4.70 \\
\hline \multirow[t]{2}{*}{ Control } & Pre-Assessment & The Stereotyped Behavior & 9.60 & 4.72 \\
\hline & Post-Assessment & The Stereotyped Behavior & 12.0 & 4.94 \\
\hline \multirow[t]{3}{*}{ Experimental } & Pre-Assessment & Self-Injurious Behavior & 11.80 & 5.35 \\
\hline & Post-Assessment & Self-Injurious Behavior & 9.0 & 4.69 \\
\hline & Follow-up Assessment & Self-Injurious Behavior & 8.40 & 4.39 \\
\hline \multirow[t]{2}{*}{ Control } & Pre-Assessment & Self-Injurious Behavior & 11.40 & 4.72 \\
\hline & Post-Assessment & Self-Injurious Behavior & 13.60 & 4.97 \\
\hline \multirow[t]{3}{*}{ Experimental } & Pre-Assessment & Compulsive Behavior & 12.0 & 3.16 \\
\hline & Post-Assessment & Compulsive Behavior & 8.60 & 3.71 \\
\hline & Follow-up Assessment & Compulsive Behavior & 8.80 & 4.14 \\
\hline \multirow[t]{2}{*}{ Control } & Pre-Assessment & Compulsive Behavior & 12.40 & 3.36 \\
\hline & Post-Assessment & Compulsive Behavior & 14.20 & 2.68 \\
\hline \multirow[t]{3}{*}{ Experimental } & Pre-Assessment & Ritualistic Behavior & 9.40 & 3.97 \\
\hline & Post-Assessment & Ritualistic Behavior & 5.60 & 2.50 \\
\hline & Follow-up Assessment & Ritualistic Behavior & 6.0 & 2.91 \\
\hline \multirow[t]{2}{*}{ Control } & Pre-Assessment & Ritualistic Behavior & 9.20 & 4.20 \\
\hline & Post-Assessment & Ritualistic Behavior & 11.40 & 5.12 \\
\hline \multirow[t]{3}{*}{ Experimental } & Pre-Assessment & Sameness Behavior & 15.80 & 2.77 \\
\hline & Post-Assessment & Sameness Behavior & 10.80 & 3.42 \\
\hline & Follow-up Assessment & Sameness Behavior & 11.0 & 3.93 \\
\hline \multirow[t]{2}{*}{ Control } & Pre-Assessment & Sameness Behavior & 15.60 & 3.28 \\
\hline & Post-Assessment & Sameness Behavior & 18.40 & 5.77 \\
\hline \multirow[t]{3}{*}{ Experimental } & Pre-Assessment & Restricted Behavior & 6.20 & 0.83 \\
\hline & Post-Assessment & Restricted Behavior & 3.60 & 1.14 \\
\hline & Follow-up Assessment & Restricted Behavior & 3.40 & 1.81 \\
\hline \multirow[t]{2}{*}{ Control } & Pre-Assessment & Restricted Behavior & 6.40 & 1.51 \\
\hline & Post-Assessment & Restricted Behavior & 8.60 & 2.70 \\
\hline
\end{tabular}

Table 1: Means and Standard Deviation of all measurements in the Experimental and Control Groups ( $N=34$ ).

Note: one participant from the control group did not participate in the follow-up assessment (treatment group participants $=17$, control group participants $=17$ ). 
The translation and validation were done by the researchers. Since the sample in this research is from Egypt, the study had to translate all of the assessment tools into the Arabic language, Egyptian dialect (see appendices A, B, and C). Researchers followed all of the required criteria to finish the translation; according to Geisinger [36] there are some steps for translations and adapting a test. All of the following steps have been considered with the three assessments that were used in this study. These were used as the procedures in the current study.

1. The first step is to translate the test's items from the English to Arabic language. And then, translate the same test back into English. Both translations were done by a fluent translator in both languages, a professor of English language at Tanta University. The second English version was compared with the original one. This is to make sure the translation is very accurate. Local dialect was taken into consideration in the final translation. Moreover the translator did not know the purpose and the aims of the test because if the translator knows that, they will try to understand and capture the meaning of the test.

2. The new translated version was reviewed by a panel of bilingual experts. Those experts reviewed the quality of translation, the items, and the adaptation. Then they wrote their comments about it. Geisinger [36] recommended that the individual panel members "(a) review the items and react in writing, (b) share their comments with one another, and (c) meet to consider the points made by each other and to reconcile any differences of opinion" (p. 306).

3. According to what the panel recommended, the translator adapted the assessment.

4. Applying the assessment as an initial trial on a small group of typical examinees from the target population. This sample determined whether the examinees were able to understand the test's items, norms, instructions and whether the time allowed for the test was long enough. One of the researchers is Egyptian, he lives there, and he was accessible for the sample to do this part.

5. An essential step is validation. It is important to decide whether the translated version measures the same qualities and the same construct as the original version, and whether the construct has meaning for the target population and their culture.

6. The final step is collecting feedback from the users. This feedback helped to adjust or revise the test in the future, and to uncover any possible misuse or misinterpretation of the test.

The researchers validated the assessment by using sample of 25 children who are different than the study sample to run reliability and validity for the assessment. The results revealed high validity via the correlation between Repetitive Behaviors Scale-Revised (RBS-R) for Children with ASD, which is a valid and reliable assessment in Egypt [37] $(r=964)$. On the other side, the researchers used the testretest technique to check the assessment reliability; results revealed a high correlation among the six subscales (stereotyped behavior $=.937$, self-injurious behavior $=.958$, compulsive behavior $=.832$, ritualistic behavior $=.964$, sameness behavior $=.873$, restricted behavior $=.934)$.

\section{Behavioral card monitoring [38]}

The behavioral card monitoring consisted of the child's name, observation time, title of observed behavior and for how many seconds this behavior was observed. The translation and validation were done by the researchers following the same six steps above.
The researchers checked the reliability by the correlation between this monitoring card and observations carried out by two counselors working in the facility who observed 10 children with ASD for 10 minutes in four days; 2.5 minutes every day in five periods of 30 seconds each. The two counselors were observing the same child at the same time, and the child did not know he/she was under observation.

The researchers found that Alpha Cronbach $=.948$, which means the assessment is highly reliable, and can be used in the study.

\section{Study Approach}

The study investigates the impact of an integrative behavioral treatment program (independent variable) on the stereotypic behavior in children with autism. It uses a quasi-experimental approach, with experimental and control groups and four-time interval assessments, including two follow-up assessments (after 15 days, and after two months).

\section{Results and Discussion}

The purpose of this study was to explore the effectiveness of an integrative early intervention program in modifying the frequency of repetitive behavior for children with ASD based on applied behavior analysis. Participants were already assigned into two groups by the researchers before the study started. The researchers then randomly selected the two groups as experimental and control. Led by a licensed professional counselor (the researcher), the first group received ten sessions from the integrative early intervention program based on applied behavior analysis. At three previously established intervals, participants' guardians were asked to complete a consent form to enrol their children in the study. Consequently, the researcher started the study by administrating the above-mentioned assessments and the early integrative approach. Statistical analyses were performed using the Pearson correlation, and Chi-squared, Mann-Whitney, and Z tests for each time assessment from the two groups to identify interaction effects.

\section{Demographic/Descriptive data}

All of the participants have been diagnosed with autism according to DSM-5 [5]. All participants in both experimental and control groups $(\mathrm{N}=34)$ have completed the pre-and post-assessments, in addition to the follow-up assessment. The means and standard deviation from both groups at each interval are shown in Table 1. The means and standard deviation for the three measurements that have been used in the study are also presented in Table 1.

\section{Results of the Main Hypotheses}

\section{Main Hypothesis}

There is a statistically significant effect of an integrative early intervention program in modifying the frequency of repetitive behavior for children with ASD (according to the total score of the repetitive behavior scale, RBS-R).

A $\mathrm{Z}$ test was conducted to evaluate the effect of an integrative early intervention program in modifying the frequency of repetitive behavior for children with ASD (according to the total score of the repetitive behavior scale, RBS-R). 
Citation: Abo Hamza EG, Helal AA (2018) The Effectiveness of Early Intensive Intervention in Modifying the Frequency of Repetitive Behavior for Children with ASD in Egypt. Int J Psychol Behav Anal 4: 152. doi: https://doi.org/10.15344/2455-3867/2018/152

Page 7 of 16

The results (Table 2 ) indicated a significant difference, $\mathrm{Z}=2.023$, $\mathrm{P}<0.01$. There is a decrease in the overall scores of the behavior measure in children with ASD in the experimental group at the post-assessment. This decline continued in the follow-up assessment (where there were no statistically significant differences between postand follow-up assessment in children with ASD in both groups in the total score of the stereotypic behavior).

The total scores of the behavioral measure of children with ASD in the control group increased at the post-measurement, $\mathrm{Z}=2.023, \mathrm{P}<$ 0.01 . Furthermore, results showed statistically significant differences between the experimental and control groups in the total score of the stereotypic behavior in the post-assessment for the experimental group, $\mathrm{Z}=2.611, \mathrm{P}<0.01$, (Frequency Mean (experimental) $=3$, Frequency Mean $($ control $)=51)$

This confirms the validity of this general hypothesis: There is a statistically significant effect of an integrative early intervention program in modifying the frequency of repetitive behavior for children with ASD (according to the overall total score of the stereotypic behavior) in a sample of children with ASD.

This conclusion is consistent with the results of several research studies, indicating that the sooner a child with ASD receives appropriate intervention based on the National Research Council's recommendations, the better the chances are to decrease deficits in language, socialization, and integrating into the community [39-50].

One of the reasons for the success of the program is that it was presented in an integrated manner dealing with all disorder aspects of children with ASD.This study also agreed with the research of Matson [46] and Zachor et al. [50], which studied the importance of continuing training for long periods until the program has the desired effectiveness.
Although the current study differs with the White [51] study on the use of negative feedback, the current study suggests using feedback in all its forms (encouraging-corrective-explanatory-reinforcement) directly $[52,53]$.

The study also agreed with Sallows and Graupner [7] and on the importance of intensive behavioral intervention, and increasing the duration of training in the program to obtain better results. The present study agreed with the study of and Corsello [40] on the importance of early intervention to treat behavioral and stereotyped problems, on the importance of early intervention with families. The present study also agreed with the study of Koegel [54], and the study of Haimedah [37] in the low rate of stereotyped behavior, but differed in the continuation of this decline after the implementation of the program.

The results also agreed with the study of the International Baccalaureate Organization [55]. The use of applied behavior analysis with early intervention reduces the severity of the characteristics of autism and increases the duration of training in the program. The efficacy of intensive early intervention using behavioral analysis, but differed in the continued effectiveness of the program after its implementation.

\section{Results of sub-Hypotheses}

The following is the results for the six sub-hypotheses, which emerged from the main hypothesis:

1. There is a statistically significant effect of an integrative training program for early intervention in modifying the stereotyped behavior (first dimension of the scale) in a sample of children with ASD.

\begin{tabular}{|l|l|l|l|l|l|l|l|l|l|}
\hline \multirow{2}{*}{ Group } & \multirow{2}{*}{ Assessment Time } & $\mathrm{N}$ & \multicolumn{2}{|c|}{ Frequency Mean } & \multicolumn{2}{|c|}{ Frequency Sum } & $\mathrm{Z}$ & Sig \\
\cline { 3 - 10 } & & & Positive & Negative & Positive & Negative & & \\
\hline Experimental & Pre/post & 17 & 0 & 3.0 & 0 & 51.0 & 2.023 & 0.05 \\
\hline Experimental & Post/follow-up & 17 & 1.50 & 1.50 & 25.50 & 25.5 & 0 & P $>.05$ \\
\hline Control & Post/follow-up & 17 & 3.0 & 0 & 51.0 & 0 & 2.023 & 0.05 \\
\hline Group & Assessment Time & $\mathrm{N}$ & \multicolumn{2}{|c|}{ Frequency Mean } & \multicolumn{2}{|c|}{ Frequency Sum } & $\mathrm{Z}$ & Sig \\
\hline Control & Pre & 17 & 5.50 & & 93.50 & & 0 & $\mathrm{P}>.05$ \\
\hline Experimental & & & 5.50 & & 93.50 & & & \\
\hline Control & Post & 17 & 8.0 & & 136.0 & & 2.611 & P $<.05$ \\
\hline Experimental & & & 3.0 & & 51.0 & & & \\
\hline
\end{tabular}

Table 2: Differences of repetitive behavior among children with ASD.

\begin{tabular}{|c|c|c|c|c|c|c|c|c|}
\hline \multirow[t]{2}{*}{ Group } & \multirow[t]{2}{*}{ Assessment Time } & \multirow[t]{2}{*}{$\mathrm{N}$} & \multicolumn{2}{|c|}{ Frequency Mean } & \multicolumn{2}{|c|}{ Frequency Sum } & \multirow[t]{2}{*}{ Z } & \multirow[t]{2}{*}{ Sig. } \\
\hline & & & Positive & Negative & Positive & Negative & & \\
\hline Experimental & Pre/post & 17 & 0 & 3.0 & 0 & 51.0 & 2.023 & $\mathrm{P}<.05$ \\
\hline Experimental & Post/follow-up & 17 & 2.50 & 2.50 & 24.5 & 24.5 & 0 & $\mathrm{P}>.05$ \\
\hline Control & Post/follow-up & 17 & 3.0 & 0 & 51.0 & 0 & 2.060 & $\mathrm{P}<.05$ \\
\hline Group & Assessment Time & $\mathrm{N}$ & \multicolumn{2}{|c|}{ Frequency Mean } & \multicolumn{2}{|c|}{ Frequency Sum } & Z & Sig. \\
\hline Control & Pre & 17 & 5.60 & & 95.2 & & 0.105 & $\mathrm{P}>.05$ \\
\hline Experimental & & & 5.40 & & 91.8 & & & \\
\hline Control & Post & 17 & 7.40 & & 125.8 & & 1.991 & $\mathrm{P}<.05$ \\
\hline Experimental & & & 3.60 & & 61.2 & & & \\
\hline
\end{tabular}

Table 3: Significance of differences in the first dimension of the scale (stereotyped behavior) amongchildren with ASD. 
Citation: Abo Hamza EG, Helal AA (2018) The Effectiveness of Early Intensive Intervention in Modifying the Frequency of Repetitive Behavior for Children with ASD in Egypt. Int J Psychol Behav Anal 4: 152. doi: https://doi.org/10.15344/2455-3867/2018/152

Page 8 of 16

The results (Table 3 ) indicated a significant difference, $\mathrm{Z}=2.023$, $\mathrm{P}<.05$. Results showed a decrease in the first dimension (stereotyped behavior) of the children with ASD in the experimental group at the post-measurement. This decline continued in the postmeasurement, where there are no significant differences between pre-and post-measurements of children in the experimental group in the first dimension (stereotyped behavior), whilst the first dimension (stereotyped behavior) in children with ASD in the control group increased at the post-measurement, $\mathrm{Z}=2.060, \mathrm{P}<.05$.

The results showed that there were statistically significant differences between the experimental and control groups in the first dimension (stereotyped behavior) at the post-assessment for the experimental group, $\mathrm{Z}=1,991, \mathrm{P}<.05,(\mathrm{M}$ (experimental $)=3.60, \mathrm{M}$ $($ control $)=7.40)$.

This confirms the validity of the first sub-hypothesis: There is a statistically significant effect of an integrative training program for early intervention in modifying patterns of behavior in a sample of children with ASD. The results of the current study were in agreement with the studies of Taylor, Hoch \& Weissman [56], Falcomata, Roane, Hovanetz, Kettering \& Kenney [57], and on the effectiveness of the training program for the experimental group. Ghanizadeh [58] and Corsello [40] agreed about the importance of early intervention for the treatment of behavioral and stereotyped problems, as well as the studies of Koegel [54], and Hamidah [37] in the effectiveness of the program in reducing stereotyped behavior.

2. There is a statistically significant effect of an integrative training program for early intervention in modifying the self-injurious behavior (second dimension of the scale) in a sample of children with ASD.

The results (Table 4) indicated that the second dimension (selfinjurious behavior) in the children with ASD in the experimental group was decreased in the post-assessment, $\mathrm{Z}=2.041, \mathrm{P}<.05$, and this decrease continued in the follow-up assessment (where there are no statistical differences between the both post- and follow-up assessment among children with autism in the second dimension (self-injurious behavior)).

While the second dimension (self-injurious behavior) among children with ASD in the control group increased at the postmeasurement it did not reach a degree of significance, $\mathrm{Z}=1.841, \mathrm{P}>.05$. The results revealed that there were no statistically significant differences between the experimental and control groups in the second dimension (self-injurious behavior) at the post-assessment, $\mathrm{Z}=1.362, \mathrm{P}>.05$.
The present study agreed with the study of Corsello [40] on the importance of early intervention to treat behavioral disorders, whilst the results differ from previous studies in the effectiveness of the program in modifying the self-injurious behavior, because the program needs a longer period of time.

3. There is a statistically significant effect of an integrative training program for early intervention in modifying the compulsive behavior (third dimension of the scale) in a sample of children with ASD.

While the third dimension (compulsive behavior) in children with ASD in the control group increased at the post-assessment, it was still not significant $(\mathrm{Z}=1.518, \mathrm{P}>.05)$. The results showed that there were statistically significant differences between the experimental and control groups in the third dimension (compulsive behavior) at the post-assessment for the experimental group, $\mathrm{Z}=2.270, \mathrm{P}<.05,(\mathrm{M}$ (experimental $)=3.40$, $\mathrm{M}($ control $)=7.60)$.

4. There is a statistically significant effect of an integrative training program for early intervention in modifying the ritualistic behavior (fourth dimension of the scale) in a sample of children with ASD.

The results (Table 6) indicated a decrease in the fourth dimension (ritualistic behavior) of the children with ASD in the experimental group at the post-measurement $(\mathrm{Z}=2.032, \mathrm{P}<.05)$. This decrease continued in the follow-up assessment (there were no statistically between the dimensional and trait measurements of children in the experimental group in the degree of fourth dimension (ritualistic behavior).

While the fourth dimension (ritualistic behavior) in children with ASD in the control group increased at the post-assessment, it was non-significant, $\mathrm{Z}=1.461, \mathrm{P}>.05$. Furthermore, the results showed that there were statistically significant differences between the experimental and control groups in the fourth dimension (ritualistic behavior) at the post-assessment for the experimental group, $\mathrm{Z}=$ $1.915, \mathrm{P}<.05,(\mathrm{M}$ (experimental $)=3.70, \mathrm{M}($ control $)=7.30)$.

This confirms the validity of the fourth sub-hypothesis, where there is a statistically significant effect of a training program for early intervention in modifying the ritualistic behavior of a sample of children with ASD. The results of the present study agreed with studies of Thompson, Iwata, Hanley, Dozier\& Samaha [60] and Smith [26] on the effectiveness of the program used, but differed in the effectiveness of the program after its implementation in the long run. The results of the study also agreed with studies of Horner, Carr,

\begin{tabular}{|c|c|c|c|c|c|c|c|c|}
\hline \multirow[t]{2}{*}{ Group } & \multirow[t]{2}{*}{ Assessment Time } & \multirow[t]{2}{*}{$\mathrm{N}$} & \multicolumn{2}{|c|}{ Frequency Mean } & \multicolumn{2}{|c|}{ Frequency Sum } & \multirow[t]{2}{*}{ Z } & \multirow[t]{2}{*}{ Sig. } \\
\hline & & & Positive & Negative & Positive & Negative & & \\
\hline Experimental & Pre/post & 17 & 0 & 3.0 & 0 & 51.0 & 2.041 & $\mathrm{P}<.05$ \\
\hline Experimental & Post/follow-up & 17 & 0 & 2.50 & 0 & 42.5 & 1.732 & $\mathrm{P}>.05$ \\
\hline Control & Post/follow-up & 17 & 2.5 & 0 & 24.5 & 0 & 1.0841 & $\mathrm{P}>.05$ \\
\hline Group & Assessment Time & $\mathrm{N}$ & \multicolumn{2}{|c|}{ Frequency Mean } & \multicolumn{2}{|c|}{ Frequency Sum } & $\mathrm{Z}$ & Sig. \\
\hline Control & Pre & 17 & 5.20 & & 88.4 & & 0.315 & $\mathrm{P}>.05$ \\
\hline Experimental & & & 5.80 & & 98.6 & & & \\
\hline Control & Post & 17 & 6.80 & & 115.6 & & 1.362 & $\mathrm{P}>.05$ \\
\hline Experimental & & & 4.20 & & 71.4 & & & \\
\hline
\end{tabular}

Table 4: Significance of differences in the second dimension of the scale (self-injurious behavior) among children with ASD. 
Citation: Abo Hamza EG, Helal AA (2018) The Effectiveness of Early Intensive Intervention in Modifying the Frequency of Repetitive Behavior for Children with ASD in Egypt. Int J Psychol Behav Anal 4: 152. doi: https://doi.org/10.15344/2455-3867/2018/152

Page 9 of 16

Strain, Todd, and Reed [61] on the effectiveness of the program used for the experimental group.

5. There is a statistically significant effect of an integrative training program for early intervention in modifying the sameness behavior (fifth dimension of the scale) in a sample of children with ASD.

The results in Table 7 indicated a decrease in the fifth dimension (sameness behavior) among children with ASD in the experimental group at the post-measurement $(\mathrm{Z}=2.060, \mathrm{P}<.05)$. This decrease continued in the follow-up assessment (there were no statistically significant differences between the post- and follow-up assessments and trait measurements in children in the experimental group in the fifth dimension (sameness behavior)). Although the fifth dimension (sameness behavior) increased at the post-assessment among children with ASD in the control group, it did not reach a level of significance, $\mathrm{Z}=1.841, \mathrm{P}>.05$
The results showed statistically significant differences between the experimental and control groups in the fifth dimension (sameness behavior) at the post-assessment among the children with ASD for the experimental group, $\mathrm{Z}=2.102, \mathrm{P}<.05,(\mathrm{M}$ (experimental $)=3.50, \mathrm{M}$ $($ control $)=7.50)$.

This result confirms the fifth sub-hypothesis, where there is a statistically significant effect of a training program for early intervention in modifying the behavior of a sample of children with ASD. The results of the present study agreed with the studies of BenItzchak \& Zachor [39], Corsello [40], Forest et al. [41], Freeman [42], Green [43], Jacobson et al. [44], Kasari [45] and Matson [46] who all focused on the importance of early intervention to treat behavioral problems and disorders.

\begin{tabular}{|l|l|l|l|l|l|l|l|l|}
\hline \multirow{2}{*}{ Group } & \multirow{2}{*}{ Assessment Time } & \multirow{2}{*}{$\mathrm{N}$} & \multicolumn{2}{|c|}{ Frequency Mean } & \multicolumn{2}{|c|}{ Frequency Sum } & $\mathrm{Z}$ & Sig. \\
\cline { 4 - 10 } & & & Positive & Negative & Positive & Negative & & \\
\hline Experimental & Pre/post & 17 & 0 & 3.0 & 0 & 51.0 & 2.041 & $\mathrm{P}<.05$ \\
\hline Experimental & Post/follow-up & 17 & 3.0 & 3.0 & 51.0 & 51.0 & 0.447 & $\mathrm{P}>.05$ \\
\hline Control & Post/follow-up & 17 & 3.25 & 2.0 & 55.25 & 34.0 & 1.518 & $\mathrm{P}>.05$ \\
\hline Group & Assessment Time & $\mathrm{N}$ & Frequency Mean & Frequency Sum & $\mathrm{Z}$ & Sig. \\
\hline Control & Pre & 17 & 5.70 & & 96.90 & & 0.211 & P $>05$ \\
\hline Experimental & & & 5.30 & & 90.1 & & & \\
\hline Control & Post & 17 & 6.70 & & 113.9 & & 2.270 & P $<.05$ \\
\hline Experimental & & & 3.40 & & 57.8 & & & \\
\hline
\end{tabular}

Table 5: Significance of differences in the third dimension of the scale (compulsive behavior) among children with ASD.

\begin{tabular}{|c|c|c|c|c|c|c|c|c|}
\hline \multirow[t]{2}{*}{ Group } & \multirow[t]{2}{*}{ Assessment Time } & \multirow[t]{2}{*}{$\mathrm{N}$} & \multicolumn{2}{|c|}{ Frequency Mean } & \multicolumn{2}{|c|}{ Frequency Sum } & \multirow[t]{2}{*}{$\mathrm{Z}$} & \multirow[t]{2}{*}{ Sig. } \\
\hline & & & Positive & Negative & Positive & Negative & & \\
\hline Experimental & Pre/post & 17 & 0 & 3.0 & 0 & 51.0 & 2.032 & $\mathrm{P}<.05$ \\
\hline Experimental & Post/follow-up & 17 & 1.5 & 0 & 25.5 & 0 & 1.414 & $\mathrm{P}>.05$ \\
\hline Control & Post/follow-up & 17 & 3.0 & 1.0 & 51.0 & 17.0 & 1.461 & $\mathrm{P}>.05$ \\
\hline Group & Assessment Time & $\mathrm{N}$ & \multicolumn{2}{|c|}{ Frequency Mean } & \multicolumn{2}{|c|}{ Frequency Sum } & $\mathrm{Z}$ & Sig. \\
\hline Control & Pre & 17 & 5.40 & & 91.8 & & 0.106 & $\mathrm{P}>.05$ \\
\hline Experimental & & & 5.60 & & 95.2 & & & \\
\hline Control & Post & 17 & 7.30 & & 124.1 & & 1.915 & $\mathrm{P}<.05$ \\
\hline Experimental & & & 3.70 & & 62.9 & & & \\
\hline
\end{tabular}

Table 6: Significance of differences in the fourth dimension of the scale (ritualistic behavior) among children with ASD.

\begin{tabular}{|c|c|c|c|c|c|c|c|c|}
\hline \multirow[t]{2}{*}{ Group } & \multirow[t]{2}{*}{ Assessment Time } & \multirow[t]{2}{*}{$\mathrm{N}$} & \multicolumn{2}{|c|}{ Frequency Mean } & \multicolumn{2}{|c|}{ Frequency Sum } & \multirow[t]{2}{*}{ Z } & \multirow[t]{2}{*}{ Sig. } \\
\hline & & & Positive & Negative & Positive & Negative & & \\
\hline Experimental & Pre/post & 17 & 0 & 3.0 & 0 & 51.0 & 2.060 & $\mathrm{P}<.05$ \\
\hline Experimental & Post/follow-up & 17 & 3.0 & 3.0 & 51.0 & 51.0 & 0.447 & $\mathrm{P}>.05$ \\
\hline Control & Post/follow-up & 17 & 2.5 & 0 & 42.5 & 0 & 1.841 & $\mathrm{P}>.05$ \\
\hline Group & Assessment Time & $\mathrm{N}$ & \multicolumn{2}{|c|}{ Frequency Mean } & \multicolumn{2}{|c|}{ Frequency Sum } & $\mathrm{Z}$ & Sig. \\
\hline Control & Pre & 17 & 5.40 & & 91.8 & & 0.108 & $\mathrm{P}>.05$ \\
\hline Experimental & & & 5.60 & & 95.2 & & & \\
\hline Control & Post & 17 & 7.50 & & 127.50 & & 2.102 & $\mathrm{P}<.05$ \\
\hline Experimental & & & 3.50 & & 9.50 & & & \\
\hline
\end{tabular}

Table 7: Significance of differences in the fifth dimension of the scale (sameness behavior) among children with ASD. 
Citation: Abo Hamza EG, Helal AA (2018) The Effectiveness of Early Intensive Intervention in Modifying the Frequency of Repetitive Behavior for Children with ASD in Egypt. Int J Psychol Behav Anal 4: 152. doi: https://doi.org/10.15344/2455-3867/2018/152

Page 10 of 16

6. There is a statistically significant effect of an integrative training program for early intervention in modifying the restricted behavior (sixth dimension of the scale) in a sample of children with ASD.

The results in Table 8 indicated a decrease in the sixth dimension (restricted behavior) among children with ASD in the experimental group at the post-measurement, $\mathrm{Z}=2.070, \mathrm{P}<.05)$. This decrease continued in the follow-up assessment (there were no statistically significant differences between the post- and follow-up assessments and trait measurements in children in the experimental group in the sixth dimension (restricted behavior)). Although the sixth dimension (restricted behavior) increased at the post-assessment among children with ASD in the control group, it did not reach a level of significance, $\mathrm{Z}=1.841, \mathrm{P}>.05$.

The results showed statistically significant differences between the experimental and control groups in the sixth dimension (restricted behavior) at the post-assessment among the children with ASD for the experimental group, $\mathrm{Z}=2.627, \mathrm{P}<.05,(\mathrm{M}$ (experimental $)=3.0, \mathrm{M}$ $($ control $)=8)$.
This result confirms the sixth sub-hypothesis, which stated there is a statistically significant effect of a training program for early intervention in modifying the restricted behavior of a sample of children with ASD. This result matches the results of other studies [53,46-50], which concluded the importance of early intervention to treat behavioral problems and disorders using behavioral therapy.

Results of the behavioral monitoring card for children with ASD in the experimental group

Each child was placed under observation for about two and a half minutes each day over a four day period (i.e. a total of ten minutes) during each of the three time intervals (before the program started, during program implementation and two months after the program was completed). The daily observation of two and a half minutes was divided into five time intervals of thirty seconds.

\section{Comment on Table 9 and Figure 2}

Table 9 and Figure 2 show an improvement in the behavior of yelling and shouting, where the frequency mean of behavior at the baseline $=14$, while the mean during the application of the program decreased to 9.5 , and it then raised to 10.75 at the follow-up assessment

\begin{tabular}{|c|c|c|c|c|c|c|c|c|}
\hline \multirow[t]{2}{*}{ Group } & \multirow[t]{2}{*}{ Assessment Time } & \multirow[t]{2}{*}{$\mathrm{N}$} & \multicolumn{2}{|c|}{ Frequency Mean } & \multicolumn{2}{|c|}{ Frequency Sum } & \multirow[t]{2}{*}{$\mathrm{Z}$} & \multirow[t]{2}{*}{ Sig. } \\
\hline & & & Positive & Negative & Positive & Negative & & \\
\hline Experimental & Pre/post & 17 & 0 & 3.0 & 0 & 51.0 & 2.070 & $\mathrm{P}<.05$ \\
\hline Experimental & Post/follow-up & 1 & 2.0 & 2.0 & 2.0 & 4.0 & 0.577 & $\mathrm{P}>.05$ \\
\hline Control & Post/follow-up & 17 & 2.5 & 0 & 42.5 & 0 & 1.841 & $\mathrm{P}>.05$ \\
\hline Group & Assessment Time & $\mathrm{N}$ & \multicolumn{2}{|c|}{ Frequency Mean } & \multicolumn{2}{|c|}{ Frequency Sum } & $\mathrm{Z}$ & Sig. \\
\hline Control & Pre & 17 & 5.60 & & 95.2 & & 0.108 & $\mathrm{P}>.05$ \\
\hline Experimental & & & 5.40 & & 91.8 & & & \\
\hline Control & Post & 17 & 8.0 & & 136 & & 2.627 & $\mathrm{P}<.05$ \\
\hline Experimental & & & 3.0 & & 51.0 & & & \\
\hline
\end{tabular}

Table 8: Significance of differences in the sixth dimension of the scale (restricted interest) among children with ASD.

\begin{tabular}{|c|c|c|c|c|c|c|c|c|c|c|}
\hline & & \multicolumn{3}{|c|}{ Before the Program } & \multicolumn{3}{|c|}{ During the Program } & \multicolumn{3}{|c|}{ Two Months after the Program } \\
\hline & & $\begin{array}{l}\text { Behavior } \\
\text { Frequency }\end{array}$ & $\begin{array}{l}\text { Partially } \\
\text { Happen }\end{array}$ & $\begin{array}{l}\text { Completely } \\
\text { Happen }\end{array}$ & $\begin{array}{l}\text { Behavior } \\
\text { Frequency }\end{array}$ & $\begin{array}{l}\text { Partially } \\
\text { Happen }\end{array}$ & $\begin{array}{l}\text { Completely } \\
\text { Happen }\end{array}$ & $\begin{array}{l}\text { Behavior } \\
\text { Frequency }\end{array}$ & $\begin{array}{l}\text { Partially } \\
\text { Happen }\end{array}$ & $\begin{array}{l}\text { Completely } \\
\text { Happen }\end{array}$ \\
\hline 1. & For 2.5 minutes & 14 & $40 \%$ & $20 \%$ & & & & & & \\
\hline 2. & For 2.5 minutes & 13 & $60 \%$ & $20 \%$ & & & & & & \\
\hline 3. & For 2.5 minutes & 14 & $80 \%$ & - & & & & & & \\
\hline 4. & For 2.5 minutes & 15 & $60 \%$ & $20 \%$ & & & & & & \\
\hline 5. & For 2.5 minutes & & & & 13 & $60 \%$ & $20 \%$ & & & \\
\hline 6. & For 2.5 minutes & & & & 10 & $60 \%$ & - & & & \\
\hline 7. & For 2.5 minutes & & & & 8 & $40 \%$ & - & & & \\
\hline 8. & For 2.5 minutes & & & & 7 & $40 \%$ & - & & & \\
\hline 9. & For 2.5 minutes & & & & & & & 9 & $40 \%$ & - \\
\hline 10. & For 2.5 minutes & & & & & & & 10 & $40 \%$ & - \\
\hline 11. & For 2.5 minutes & & & & & & & 12 & $40 \%$ & $20 \%$ \\
\hline 12. & For 2.5 minutes & & & & & & & 12 & $60 \%$ & $20 \%$ \\
\hline Total & & 56 & $M=14.56$ & 38 & & $M=.9$ & & 43 & $\mathrm{M}=75.01$ & \\
\hline
\end{tabular}

Table 9: Frequency of the behavior of "yelling and shouting", during the number of observations in the first case in the experimental group at different stages of intervention. 
Citation: Abo Hamza EG, Helal AA (2018) The Effectiveness of Early Intensive Intervention in Modifying the Frequency of Repetitive Behavior for Children with ASD in Egypt. Int J Psychol Behav Anal 4: 152. doi: https://doi.org/10.15344/2455-3867/2018/152

Page 11 of 16

(after two months). Figure 2 shows the level of improvement during the application period during observations $(5,6,7,8)$.

Each child was placed under observation (for 10 minutes) intermittently within four days for about two and a half minutes during the three-time interval (before the program, during program implementation and two months after the program was completed) The interval system, divided by $2 \frac{1}{2}$ minutes into five-time intervals, is observed for 30 seconds.

\section{Comment on Table 10 and Figure 3}

Table 10 and Figure 3 show an improvement in the behavior of hand flapping, where the mean at the baseline $=25$, which decreased to 14.5 during implementation of the program, and then raised to 17.5 at the follow-up assessment. Figure 2 shows the level of improvement during the implementation period during observations 5-8.

Figure 3 shows the level of improvement during the application period during observations $(5,6,7,8)$. The prevalence of behavior during the baseline observations was found in the baseline observation at $20 \%$ of the observation periods, while it was spread and occurs partially during $20 \%$ of observation periods. While the eighth observation during application of the program was the first does not occur on a continuous basis, but was happening partially during $40 \%$ of the observation periods. While returning two months after the end of the program to occur continuously during $20 \%$ of observation periods (observation 12) and occurs partially during $40 \%$ of the observation periods.

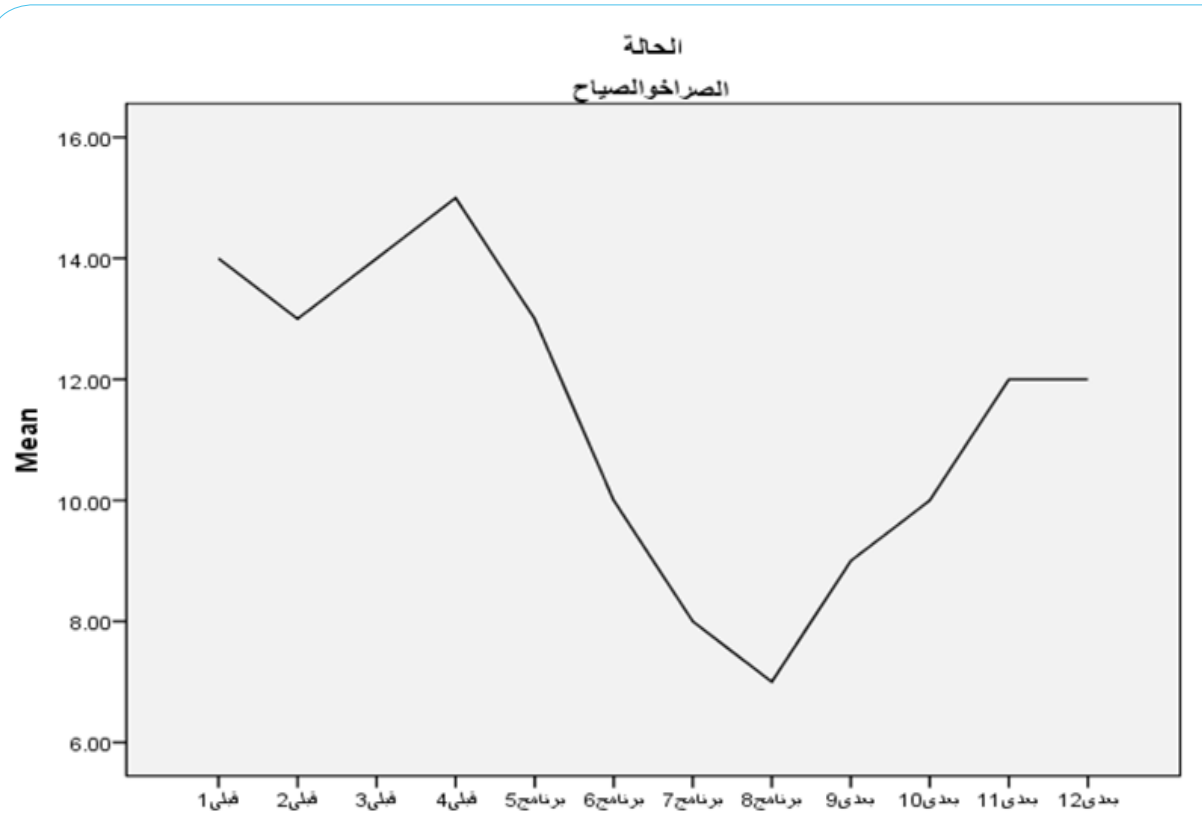

Figure 2: Frequency of behavior (yelling and shouting) is shown in the first case at different stages of intervention.

\begin{tabular}{|c|c|c|c|c|c|c|c|c|c|c|}
\hline & \multicolumn{3}{|c|}{ Before the Program } & \multicolumn{3}{|c|}{ During the Program } & \multicolumn{3}{|c|}{ Two Months after the Program } \\
\hline & & $\begin{array}{l}\text { Behavior } \\
\text { Frequency }\end{array}$ & $\begin{array}{l}\text { Partially } \\
\text { Happen }\end{array}$ & $\begin{array}{l}\text { Completely } \\
\text { Happen }\end{array}$ & $\begin{array}{l}\text { Behavior } \\
\text { Frequency }\end{array}$ & $\begin{array}{l}\text { Partially } \\
\text { Happen }\end{array}$ & $\begin{array}{l}\text { Completely } \\
\text { Happen }\end{array}$ & $\begin{array}{l}\text { Behavior } \\
\text { Frequency }\end{array}$ & $\begin{array}{l}\text { Partially } \\
\text { Happen }\end{array}$ & $\begin{array}{l}\text { Completely } \\
\text { Happen }\end{array}$ \\
\hline 1. & For 2.5 minutes & 25 & $20 \%$ & $20 \%$ & & & & & & \\
\hline 2. & For 2.5 minutes & 24 & $20 \%$ & $20 \%$ & & & & & & \\
\hline 3. & For 2.5 minutes & 22 & $60 \%$ & - & & & & & & \\
\hline 4. & For 2.5 minutes & 18 & $60 \%$ & - & & & & & & \\
\hline 5. & For 2.5 minutes & & & & 16 & $60 \%$ & $20 \%$ & & & \\
\hline 6. & For 2.5 minutes & & & & 14 & $40 \%$ & - & & & \\
\hline 7. & For 2.5 minutes & & & & 15 & $60 \%$ & - & & & \\
\hline 8. & For 2.5 minutes & & & & 13 & $40 \%$ & - & & & \\
\hline 9. & For 2.5 minutes & & & & & & & 15 & $80 \%$ & - \\
\hline 10. & For 2.5 minutes & & & & & & & 17 & $80 \%$ & - \\
\hline 11. & For 2.5 minutes & & & & & & & 18 & $60 \%$ & - \\
\hline 12. & For 2.5 minutes & & & & & & & 20 & $40 \%$ & $20 \%$ \\
\hline Total & & 89 & $M=25.22$ & & 58 & $\mathrm{M}=5.41$ & & 70 & $\mathrm{M}=5.71$ & \\
\hline
\end{tabular}

Table 10: Frequency of the behavior of "hand flapping", during the number of observations in the second case in the experimental group at different stages of intervention 
Citation: Abo Hamza EG, Helal AA (2018) The Effectiveness of Early Intensive Intervention in Modifying the Frequency of Repetitive Behavior for Children with ASD in Egypt. Int J Psychol Behav Anal 4: 152. doi: https://doi.org/10.15344/2455-3867/2018/152

Page 12 of 16

\section{Comment on Table 11 and Figure 4}

Table 11 and Figure 4 show an improvement in the behavior of shaking the head with circular motion. The average frequency of behavior at the baseline $=15$, while this average decreased during application of the program to 8.25 , and it rose at the trace measurement (after two months) to 14

Figure 4 shows the level of improvement during implementation the program during observations 5-8. Figure 4 shows the level of improvement during the application period during observations (5, $6,7,8)$. The prevalence of behavior during the baseline observations was found in the baseline observation at $20 \%$ of observation periods, while it was spread and occurs partially during $40 \%$ of observation periods.
While the eighth observation during application of the program was the first does not occur on a continuous basis, but was happening partially during $40 \%$ of the observation periods.

However, two months of the end of the program it occurred partially during $40 \%$ of the observation periods, while it did not occur continuously during the observation period.

Each child was placed under observation (for 10 minutes) intermittently within four days for about two and a half minutes during the three basic stages (baseline, during program implementation, and two months after the program was completed). The interval system, divided by $2 \frac{1}{2}$ minutes into five-time intervals, is observed for 30 seconds.

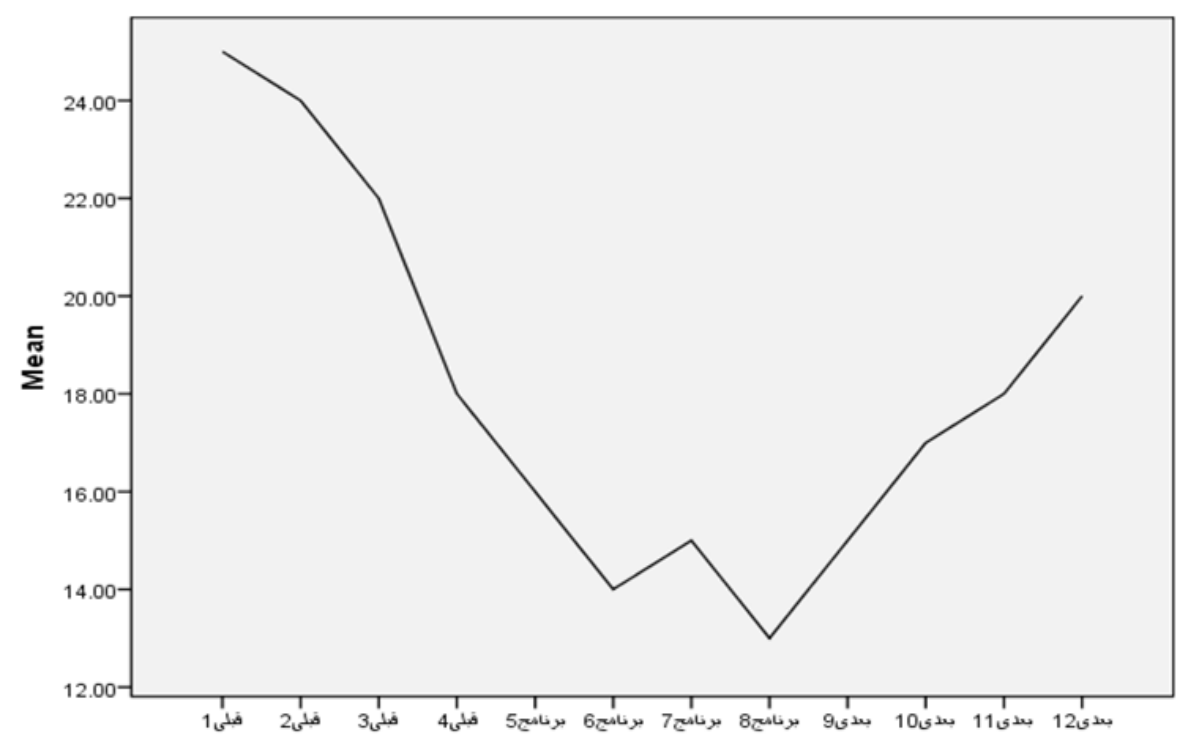

Figure 3: Frequency of behavior (hand flapping) in the second case at different stages of intervention.

\begin{tabular}{|c|c|c|c|c|c|c|c|c|c|c|}
\hline & \multicolumn{3}{|c|}{ Before the Program } & \multicolumn{3}{|c|}{ During the Program } & \multicolumn{3}{|c|}{ Two Months after the Program } \\
\hline & & $\begin{array}{l}\text { Behavior } \\
\text { Frequency }\end{array}$ & $\begin{array}{l}\text { Partially } \\
\text { Happen }\end{array}$ & $\begin{array}{l}\text { Completely } \\
\text { Happen }\end{array}$ & $\begin{array}{l}\text { Behavior } \\
\text { Frequency }\end{array}$ & $\begin{array}{l}\text { Partially } \\
\text { Happen }\end{array}$ & $\begin{array}{l}\text { Completely } \\
\text { Happen }\end{array}$ & $\begin{array}{l}\text { Behavior } \\
\text { Frequency }\end{array}$ & $\begin{array}{l}\text { Partially } \\
\text { Happen }\end{array}$ & $\begin{array}{l}\text { Completely } \\
\text { Happen }\end{array}$ \\
\hline 1. & For 2.5 minutes & 15 & $60 \%$ & $20 \%$ & & & & & & \\
\hline 2. & For 2.5 minutes & 13 & $60 \%$ & - & & & & & & \\
\hline 3. & For 2.5 minutes & 14 & $80 \%$ & - & & & & & & \\
\hline 4. & For 2.5 minutes & 15 & $60 \%$ & $20 \%$ & & & & & & \\
\hline 5. & For 2.5 minutes & & & & 10 & $60 \%$ & $20 \%$ & & & \\
\hline 6. & For 2.5 minutes & & & & 8 & $40 \%$ & - & & & \\
\hline 7. & For 2.5 minutes & & & & 7 & $40 \%$ & - & & & \\
\hline 8. & For 2.5 minutes & & & & 8 & $40 \%$ & - & & & \\
\hline 9. & For 2.5 minutes & & & & & & & 13 & $60 \%$ & - \\
\hline 10. & For 2.5 minutes & & & & & & & 14 & $40 \%$ & - \\
\hline 11. & For 2.5 minutes & & & & & & & 14 & $80 \%$ & $20 \%$ \\
\hline 12. & For 2.5 minutes & & & & & & & 15 & $80 \%$ & - \\
\hline Total & & 57 & $\mathrm{M}=25.41$ & & 33 & $M=25.8$ & & 56 & $M=41$ & \\
\hline
\end{tabular}

Table 11: Frequency of the behavior of "shaking the head with circular motion", during the number of observations in the third case in the experimental group at different stages of intervention 
Citation: Abo Hamza EG, Helal AA (2018) The Effectiveness of Early Intensive Intervention in Modifying the Frequency of Repetitive Behavior for Children with ASD in Egypt. Int J Psychol Behav Anal 4: 152. doi: https://doi.org/10.15344/2455-3867/2018/152

Page 13 of 16

\section{Comment on Table 12 and Figure 5}

Table 12 and Figure 5 show an improvement in the behavior of attachment to electronics such as a tablet computer. The mean of this behavior at baseline $=12$, which reduced to 6.75 and then increased at the trace measurement (after two months) to 9.5.

Furthermore, Figure 4 shows the level of improvement during the implementation period observations 5-8.

The prevalence of behavior during the baseline observations was found in the baseline observation at $20 \%$ of the observation periods, while it was spread and occurs partially during $60 \%$ of observation periods. While the eighth observation during application of the program does not occur on a continuous basis, it happened partially during $40 \%$ of the observation periods.

In the third-time assessment, two months after the end of the program, it occurred continuously during $20 \%$ of observation periods (observation 12) and occurs partially during $40 \%$ of the observation periods.

Each child was placed under observation (for 10 minutes) intermittently within four days for about two and a half minutes during the three basic stages (baseline, during program implementation, and two months after the program was completed). The interval system, divided by $2^{1 / 2}$ minutes into five-time intervals, is observed for 30 seconds.

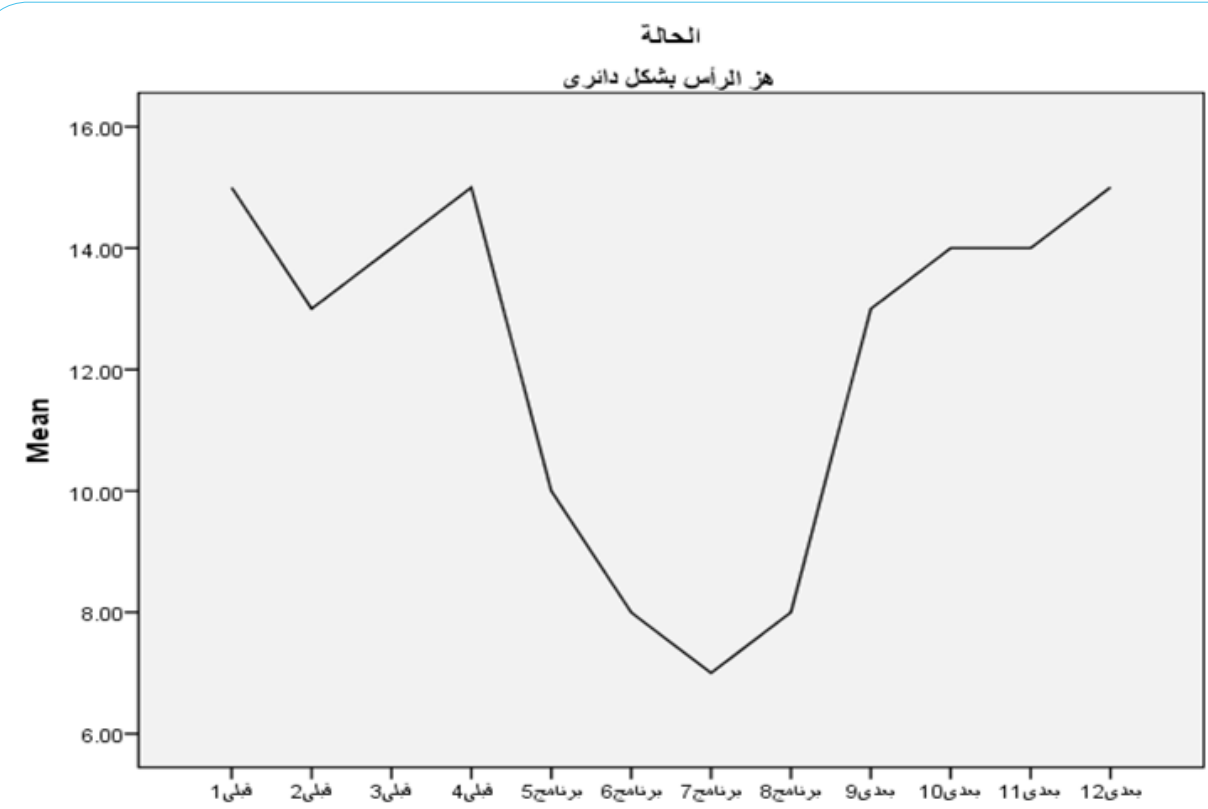

Figure 4: The frequency of behavior (shaking the head with circular motion) in the second case at different stages of intervention.

\begin{tabular}{|c|c|c|c|c|c|c|c|c|c|c|}
\hline & \multicolumn{3}{|c|}{ Before the Program } & \multicolumn{3}{|c|}{ During the Program } & \multicolumn{3}{|c|}{ Two Months after the Program } \\
\hline & & $\begin{array}{l}\text { Behavior } \\
\text { Frequency }\end{array}$ & $\begin{array}{l}\text { Partially } \\
\text { Happen }\end{array}$ & $\begin{array}{l}\text { Completely } \\
\text { Happen }\end{array}$ & $\begin{array}{l}\text { Behavior } \\
\text { Frequency }\end{array}$ & $\begin{array}{l}\text { Partially } \\
\text { Happen }\end{array}$ & $\begin{array}{l}\text { Completely } \\
\text { Happen }\end{array}$ & $\begin{array}{l}\text { Behavior } \\
\text { Frequency }\end{array}$ & $\begin{array}{l}\text { Partially } \\
\text { Happen }\end{array}$ & $\begin{array}{l}\text { Completely } \\
\text { Happen }\end{array}$ \\
\hline 1. & For 2.5 minutes & 12 & $60 \%$ & $20 \%$ & & & & & & \\
\hline 2. & For 2.5 minutes & 10 & $60 \%$ & - & & & & & & \\
\hline 3. & For 2.5 minutes & 11 & $80 \%$ & - & & & & & & \\
\hline 4. & For 2.5 minutes & 11 & $60 \%$ & - & & & & & & \\
\hline 5. & For 2.5 minutes & & & & 8 & $60 \%$ & $20 \%$ & & & \\
\hline 6. & For 2.5 minutes & & & & 7 & $60 \%$ & - & & & \\
\hline 7. & For 2.5 minutes & & & & 6 & $40 \%$ & - & & & \\
\hline 8. & For 2.5 minutes & & & & 6 & $40 \%$ & - & & & \\
\hline 9. & For 2.5 minutes & & & & & & & 11 & $60 \%$ & - \\
\hline 10. & For 2.5 minutes & & & & & & & 12 & $40 \%$ & $20 \%$ \\
\hline 11. & For 2.5 minutes & & & & & & & 12 & $60 \%$ & - \\
\hline 12. & For 2.5 minutes & & & & & & & 13 & $40 \%$ & $20 \%$ \\
\hline Total & & 44 & $M=11$ & & 27 & $M=75.6$ & & 38 & $M=5.9$ & \\
\hline
\end{tabular}

Table 12 : Frequency of the behavior of "attachment to electronics (tablet computer)", during the number of observations in the fourth case in the experimental group at different stages of interventio 
Citation: Abo Hamza EG, Helal AA (2018) The Effectiveness of Early Intensive Intervention in Modifying the Frequency of Repetitive Behavior for Children with ASD in Egypt. Int J Psychol Behav Anal 4: 152. doi: https://doi.org/10.15344/2455-3867/2018/152

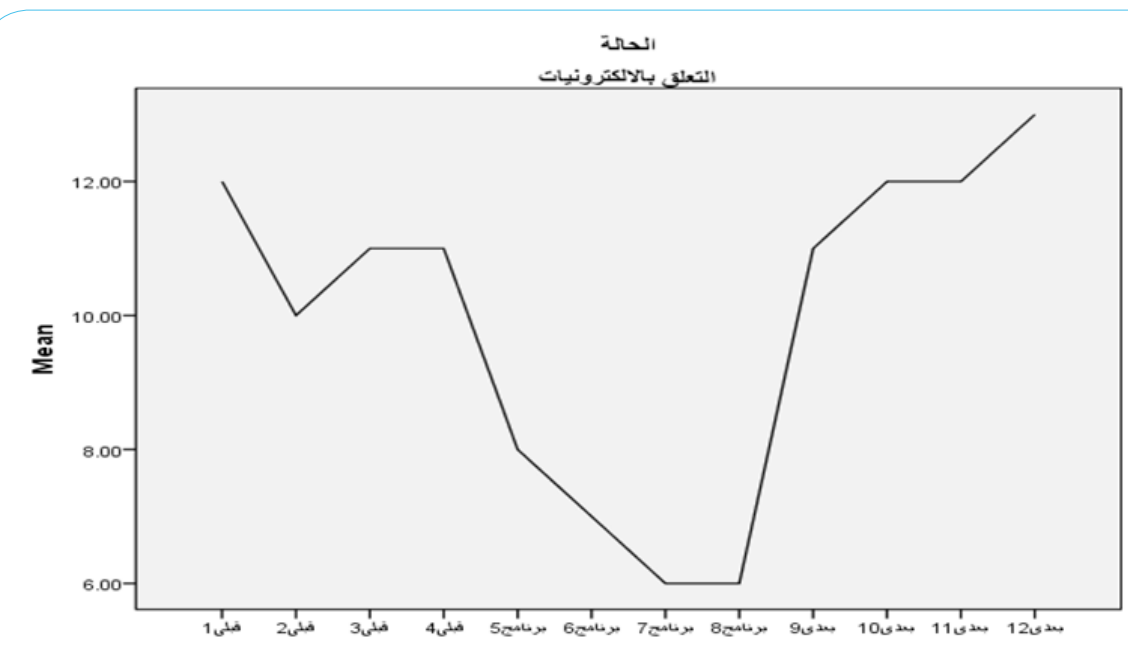

Figure 5: The frequency of behavior (attachment to electronics "tablet computer") in the second case at different stages of intervention.

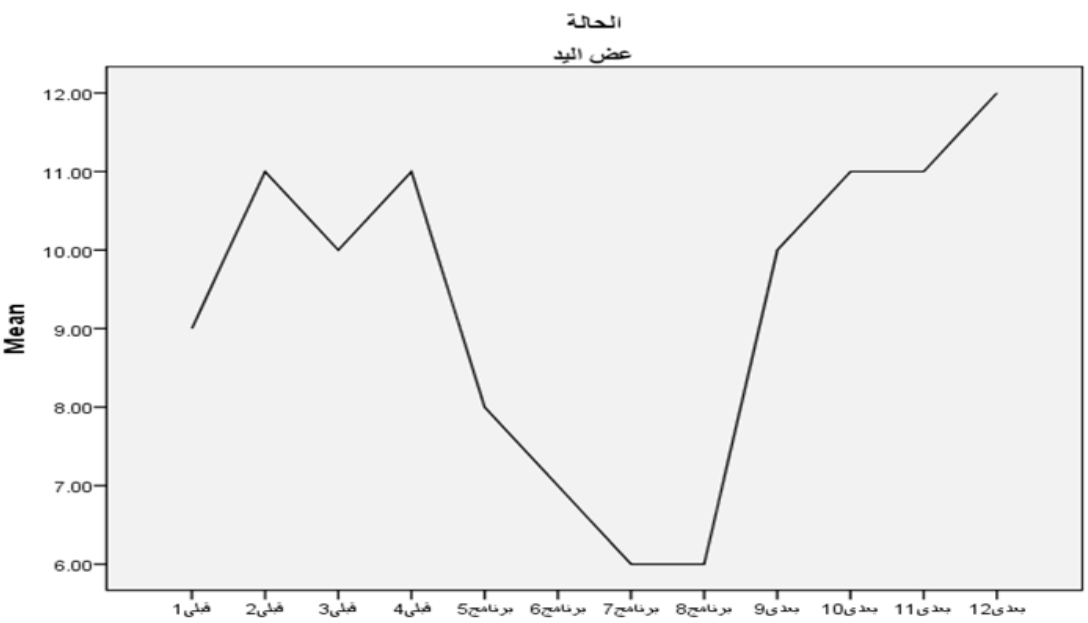

Figure 6: The frequency of "hand biting behavior" in the second case at different stages of intervention.

\begin{tabular}{|c|c|c|c|c|c|c|c|c|c|c|}
\hline & & \multicolumn{3}{|c|}{ Before the Program } & \multicolumn{3}{|c|}{ During the Program } & \multicolumn{3}{|c|}{ Two Months after the Program } \\
\hline & & $\begin{array}{l}\text { Behavior } \\
\text { Frequency }\end{array}$ & $\begin{array}{l}\text { Partially } \\
\text { Happen }\end{array}$ & $\begin{array}{l}\text { Completely } \\
\text { Happen }\end{array}$ & $\begin{array}{l}\text { Behavior } \\
\text { Frequency }\end{array}$ & $\begin{array}{l}\text { Partially } \\
\text { Happen }\end{array}$ & $\begin{array}{l}\text { Completely } \\
\text { Happen }\end{array}$ & $\begin{array}{l}\text { Behavior } \\
\text { Frequency }\end{array}$ & $\begin{array}{l}\text { Partially } \\
\text { Happen }\end{array}$ & $\begin{array}{l}\text { Completely } \\
\text { Happen }\end{array}$ \\
\hline 1. & For 2.5 minutes & 9 & $60 \%$ & $20 \%$ & & & & & & \\
\hline 2. & For 2.5 minutes & 11 & $80 \%$ & - & & & & & & \\
\hline 3. & For 2.5 minutes & 10 & $80 \%$ & - & & & & & & \\
\hline 4. & For 2.5 minutes & 11 & $80 \%$ & - & & & & & & \\
\hline 5. & For 2.5 minutes & & & & 8 & $40 \%$ & - & & & \\
\hline 6. & For 2.5 minutes & & & & 7 & $60 \%$ & - & & & \\
\hline 7. & For 2.5 minutes & & & & 6 & $40 \%$ & - & & & \\
\hline 8. & For 2.5 minutes & & & & 6 & $40 \%$ & - & & & \\
\hline 9. & For 2.5 minutes & & & & & & & 10 & $60 \%$ & - \\
\hline 10. & For 2.5 minutes & & & & & & & 11 & $80 \%$ & - \\
\hline 11. & For 2.5 minutes & & & & & & & 11 & $80 \%$ & - \\
\hline 12. & For 2.5 minutes & & & & & & & 12 & $60 \%$ & $20 \%$ \\
\hline Total & & 41 & $\mathrm{M}=25.01$ & & 27 & $M=75.6$ & & 44 & $M=11$ & \\
\hline
\end{tabular}

Table 13: Frequency ofbehavior (hand biting), during the number of observationsin thefifth casein the experimentalgroup at different stages of intervention. 
Citation: Abo Hamza EG, Helal AA (2018) The Effectiveness of Early Intensive Intervention in Modifying the Frequency of Repetitive Behavior for Children with ASD in Egypt. Int J Psychol Behav Anal 4: 152. doi: https://doi.org/10.15344/2455-3867/2018/152

Page 15 of 16

\section{Comment on Table 13 and Figure 6}

Table 13 and Figure 6 show an improvement in hand biting behavior. The mean of behavior at baseline was 9 , while the average during the application of the program decreased to 6.75 and it then increased in the follow-up assessment (after two months) to 11. Figure 6 shows the level of improvement during the implementation period during observations 5-8.

Figure 6 shows the level of improvement during the application period during observations $(5,6,7,8)$. The prevalence of behavior during the baseline observations was found in the baseline observation at $20 \%$ of the observation periods, while it was spread and occurs partially during $60 \%$ of observation periods.

While the eighth observation during application of the program was the first does not occur on a continuous basis, but was happening partially during $40 \%$ of the observation periods.

In the third-time assessment, two months after the end of the program, it occurred continuously during $20 \%$ of observation periods (observation 12) and occurs partially during $60 \%$ of the observation periods.

\section{Recommendations of the Study}

The results of this study present many recommendations as follows

1. Continuation of the application of the training program based on applied behavior analysis for a longer period of intensive effort, and integration between the specialist and the family, to give more positive results.

2. Highlighting the needs of special needs in general, and especially within groups such as autistics; to raise the level of awareness in the community of these categories and how to deal with them.

3. Preparation of guidance programs for parents to familiarize themselves with the nature of autism, and work to provide educational programs guiding the possibility of trying to understand some of the behaviors of these children and ways of dealing with them according to treatment plans.

4. Obtain media coverage of the importance of early diagnosis and intervention to modify the behavior of children with ASD

\section{Competing Interests}

The authors declare that they have no competing interests.

\section{References}

1. Bodfish JW, Symons FJ, Lewis MH (2000) The Repetitive Behavior ScaleRevised. Western Carolina Center Research.

2. Reichow B, Wolery M (2009) Comprehensive synthesis of early intensive behavioral interventions for young children with autism based on the UCLA Young Autism Project model. J Autism Dev Disord 39: 23-41.

3. Reichow B (2012) Overview of meta-analyses on early intensive behavioral intervention for young children with autism spectrum disorders. J Autism Dev Disord 42: 512-520.

4. Center for Disease Control and Prevention (2007) Prevalence of the autism spectrum disorders (ASDs) in multiple areas of the United States, 2000 and 2002.

5. American Psychiatric Association (2013) Diagnostic and statistical manual of mental disorders. (5th ed) Washington, DC.
6. Smith RG, Russo L, Le LD (1999) Distinguishing between extinction and punishment effects of response blocking: A replication. J Appl Behav Anal 32: $367-370$.

7. Sallows GO, Graupner TD (2005) Intensive reatment for children with autism: Four-year outcome and predictors. Am J Ment Retard 110: 417-438.

8. Cohen H, Amerine-Dickens M, Smith T (2006) Early intensive behaviora treatment: Replication of the UCLA model in a community setting. J Dev Behav Pediatr 27: S145-S155.

9. Hussein $H$, Taha GR, Almanasef A (2011) Characteristics of autism spectrum disorders in a sample of Egyptian and Saudi patients. Child Adolesc Psychiatry Ment Health 5: 2-12.

10. Elhamid A, Howe A, Reading R (2009) Prevalence of emotional and behavioural problems among 6-12 year old children in Egypt. Social Psychiatry \& Psychiatric Epidemiology 44: 8-14

11. Lam KSL, Aman MG (2007) The repetitive behavior scale-revised: Independent validation in individuals with autism spectrum disorders. J Autism Dev Disord 37: 855-866.

12. Lewis $\mathrm{MH}$, Bodfish JW (1998) Repetitive behavior disorders in autism Intellectual Disability and Developmental Disabilities Research Reviews 4 80-89.

13. Turner M (1999) Annotation: Repetitive behaviour in autism: A review of psychological research. J Child Psychol Psychiatry 40: 839-849.

14. Baren-Cohen S, Tager-Flusberg H, Cohen DJ (2000) Understanding other minds: Perspectives from developmental cognitive neuroscience. (2nd ed). Oxford: Oxford University Press.

15. Szatmari P, Bryson SE, Boyle MH, Streiner DL, Duku, E, et al. (2003) Predictors of outcome among high functioning children with autism and Asperger syndrome. Journal of Child Psychology and Psychiatry 44: 520-528.

16. Ronald A, Happé F, Bolton P, Butcher LM, Price TS, et al. (2006) Genetic heterogeneity between the three components of the autism spectrum: $A$ twin study. J Am Acad Child Adolesc Psychiatry 45: 692-699.

17. Silverman JM, Smith CJ, Schmeidler J, Hollander E, Lawlor BA, et al. (2002) Symptom domains in autism and related conditions: Evidence for familiarity. Am J Med Genet 114: 64-73.

18. Matson JL (1995) The Diagnostic Assessment for the Severely HandicappedRevised (DASH-II). Baton Rouge, LA: Scientific Publishers.

19. Matson JL, Rush KS, Hamilton M, Anderson SJ, Bamburg JW. et al.(1996) Characteristics of autism as assessed by the Diagnostic Assessment for the Severely Handicapped-II (DASH-II). Res Dev Disabil 17: 135-143.

20. Evans DW, Gray FL (2000) Compulsive-like behavior in individuals with down syndrome: Its relation to mental age level, adaptive and maladaptive behavior. Child Dev 71: 288-300.

21. American Psychiatric Association (2000) Diagnostic and statistical manual of mental disorders. 4th ed, text revision. Washington, DC.

22. McDougle CJ, Kresch LE, Goodman WK, Naylor ST, Volkmar FR, et al. (1995) A case-controlled study of repetitive thoughts and behavior in adults with autistic disorder and obsessive-compulsive disorder. Am J Psychiatry 152: 772-777.

23. Birnbrauer JS, Leach DJ (1993) The Murdoch Early Intervention Program after 2 years. Behavior Change 10 63-74.

24. McEachin JJ, Smith T, Lovaas OI (1993) Long-term outcome for children with autism who received early intensive behavioral treatment. Am J Ment Retard 97: 359-372.

25. Lovaas OI (1987) Behavioral treatment and normal educational and intellectual functioning in young children with ASD. J Consult Clin Psychol 55: 3-9.

26. Smith T (1999) Outcome of early intervention for children with autism Clinical Psychology: Science and Practice 6: 33-49.

27. Green VA, Pituch KA, Itchon J, Choi A, O'Reilly M, et al. (2006) Internet survey of treatments used by parents of children with autism. Res Dev Disabil 27: 70-84.

28. Harris SL, Handleman JS, Gordon R, Kristoff B, Fuentes F, et al. (1991) Changes in cognitive and language functioning of preschool children with autism. J Autism Dev Disord 21: 281-290.

29. Maurice C (1993) Let Me Hear Your Voice: A Family's Triumph Over Autism. New York: Knopf

Int J Psychol Behav Anal

ISSN: 2456-3501

IJPBA, an open access journal

Volume 4. 2018. 152 
Citation: Abo Hamza EG, Helal AA (2018) The Effectiveness of Early Intensive Intervention in Modifying the Frequency of Repetitive Behavior for Children with ASD in Egypt. Int J Psychol Behav Anal 4: 152. doi: https://doi.org/10.15344/2455-3867/2018/152

Page 16 of 16

30. Perry R, Cohen I, DeCarlo R (1995) Case study: Deterioration, autism, and recovery in two siblings. J Am Acad Child Adolesc Psychiatry 34: 232-237.

31. Fenske BC, Zalenski S, Krantz PJ, McClannahan LE (1985) Age at intervention and treatment outcome for children with ASD in a comprehensive intervention program. Analysis and Intervention in Developmenta Disabilities 5: 49-58.

32. Eikeseth S, Smith T, Jahr E, Eldevik S (2012) Effects of low intensity behavioral treatment for children with autism and mental retardation. J Autism Dev Disord 36: 211-224.

33. Howard JS, Sparkman CR, Cohen HG, Green G, Stanislaw H, et al. (2005) A comparison of intensive behavior analytic and eclectic treatments for young children with autism. Res Dev Disabil 26: 359-383.

34. Cooper J, Heron T, Heward W (1987) Applied behavior analysis. Columbus: Merrill Pub Co.

35. Bodfish JW, Symons FJ, Parker DE, Lewis MH (2000) Varieties of repetitive behavior in autism: Comparisons to intellectual disability. J Autism Dev Disord 30: 237-243

36. Geisinger KF (1994) Cross-cultural normative assessment: Translation and adaptation influencing the normative interpretation of assessment instruments. Psychological Assessment 4: 304-312.

37. Haimedah R (2007) Psychology of Disability. Anglo Masria Cairo, Egypt.

38. Matson JL (2009) Applied behavior analysis for children with autism spectrum disorders. New York: Springer-Verlag.

39. Ben-Itzchak E, Zachor A (2007) The effects of intellectual functioning and autism severity on outcome of early behavioral intervention for children with autism. Res Dev Disabil 28: 287-303.

40. Corsello CM (2005) Early intervention in autism. Infants \& Young Children 18: 74-85.

41. Forest EJ, Horner RH, Lewis-Palmer T, Todd AW, McGee G (2004) Transitions for young children with autism from preschool to kindergarten. Journal of Positive Behavior Interventions 6: 103-112.

42. Freeman BJ (1997) Guidelines for evaluating intervention programs for children with autism. J Autism Dev Disord 27: 641-651.

43. Green $\mathrm{G}$ (1996) Early behavioral intervention for autism: What does research tell us? Behavioral intervention for young children with autism. Austin, TX: ProEd.

44. Jacobson JW, Mulick JA, Green G (1998) Cost-benefit estimates for early intensive behavioral intervention for young children with autism-general model and single state case. Behavioral Interventions 13: 201-226.

45. Kasari C (2002) Assessing change in early intervention programs for children with autism. Journal of Autism and Developmental Disorders 32: 447-461.

46. Matson JL (2007) Determining treatment outcome in early intervention programs for autism spectrum disorders: A critical analysis of measurement issues in learning based interventions. Res Dev Disabil 28: 207-218.

47. McGovern CW, Sigman M (2005) Continuity and change from early childhood to adolescence in autism. J Child Psychol Psychiatry 46: 401-408.

48. Reynolds AJ (1995) One year of preschool intervention or two: Does it matter? Early Childhood Research Quarterly 10: 1-31.

49. Steele MM (2004) Making the case for early identification and intervention for young children at risk for learning disabilities. Early Childhood Education Journal 32: 75-91.

50. Zachor DA, Ben-Itzchak E, Rabinovich A, Lahat E (2007) Change in autism core symptoms with intervention. Research in Autism Spectrum Disorders 1: 304-317.

51. White SJ (2000) The effects of feedback on learning in discrete trial teaching of children with autism. Dissertation Abstracts International 38: 1102

52. Ahearn WH, Clark KM, MacDonald RPF (2007) Assessing and treating vocal stereotypy in children with autism. J Appl Behav Anal 40: 263-275.

53. Petrus C, Adamson SR, Block L, Einarson SJ, Sharifnejad M, et al. (2008) Effects of exercise interventions on stereotypic behaviours in children with autism spectrum disorder. Physiother Can 60: 134-145.

54. Koegel RL, Koegel LK (1990) Extended reductions in stereotypic behavior of students with autism through a self-management treatment package. J Appl Behav Anal 23: 119-127.

55. International Baccalaureate Organization (2008) Applied behavior analysis and early intervention, 50 Excellent Extended Essays.
56. Taylor BA, Hoch H, Potter B, Rodriguez A, Spinnato D, et al. (2005) Manipulating establishing operations to promote initiations toward peers in children with autism. Res Dev Disabil 26: 385-392.

57. Falcomata TS, Roane HS, Hovanetz AN, Kettering TL, Kenney KM, et al. (2004) An evaluation of response cost in the treatment of inappropriate vocalizations maintained by automatic reinforcement. J Appl Behav Anal 37: 83-87.

58. Ghanizadeh A (2010) Clinical approach to motor stereotypies in children Iran J Pediatr 20: 149-159.

59. Thompson $\mathrm{RH}$, Iwata BA, Hanley GP, Dozier CL, Samaha AL, et al. (2003) The effects of extinction, noncontingent reinforcement, and differential reinforcement of other behavior as control procedures. J Appl Behav Anal 36: 221-238.

60. Horner RH, Carr EG, Strain PS, Todd AW, Reed HK et al. (2002) Problem behavior interventions for young children with autism: A research synthesis. J Autism Dev Disord 32: 423-446. 